\title{
Scientists on trial over L'Aquila deaths
}

\author{
Seismologists charged for giving apparent reassurances on Italian earthquake risks.
}

\section{BY NICOLA NOSENGO IN ROME}

$\mathrm{T}$ The perils of communicating scientific uncertainty when under the media spotlight are set to be probed in an Italian court later this year. The case, which was given the go-ahead by a judge last week, involves six Italian seismologists and one government official. They will be tried this autumn for the manslaughter of some of the 309 people who died in the earthquake that struck the city of L'Aquila on 6 April 2009. If convicted, they could face jail sentences of up to 12 years.

The seven were on a committee tasked with assessing the risks of increased seismic activity in the area. At a press conference following a committee meeting a week before the earthquake, some members assured the public that they were in no danger. After the quake, many of the victims' relatives said that because of these reassurances they did not take precautionary measures, such as leaving their homes.

L'Aquila's public prosecutor, Fabio Picuti, argued last week that although the committee members could not have predicted the earthquake, they had translated their scientific uncertainty into an overly optimistic message. The prosecution has focused on a statement made at the press conference by accused committee member Bernardo De Bernardinis, who was then deputy technical head of Italy's Civil Protection Agency. "The scientific community tells me there is no danger," he said at the time, "because there is an ongoing discharge of energy. The situation looks favourable."

Many seismologists - including one of the accused, Enzo Boschi, president of the National Institute of Geophysics and Vulcanology in Rome - have since criticized the statement as scientifically unfounded. The statement does not appear in the minutes of the committee meeting itself, and the accused seismologists say they cannot be blamed for it. De Bernardinis's advocate insists that his client merely summarized what the scientists had told him. The prosecutor claims that because none of the other committee members immediately corrected De Bernardinis, they are all equally culpable.

Boschi says that he is "devastated" by the ruling. He notes that there are hundreds of seismic shocks every year in Italy: "If we were to alert the population every time, we would probably be indicted for unjustified alarm," he said, adding that poor building standards were the main cause of the tragedy.

Vincenzo Vittorini, a physician in L'Aquila whose wife and daughter were killed in the earthquake and who is president of the local victims' association, hopes the trial will lead to a thorough investigation into what went wrong. "Nobody here wants to put science in the dock", he says. "All we wanted was clearer information on risks in order to make our choices".

\section{Japan quake rocks fusion project}

\section{Damaged facilities force further delay to ITER experiment.}

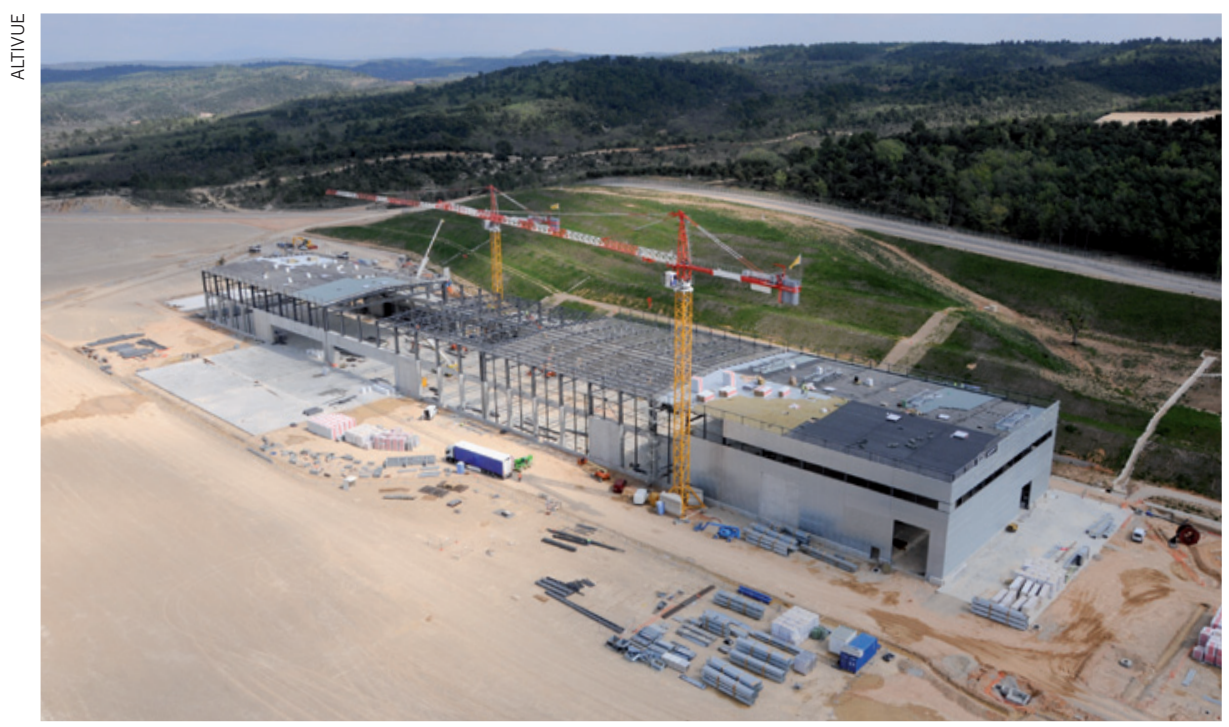

Construction of the ITER fusion reactor in France is beset by financial and technical problems.
BY GEOFF BRUMFIEL

IN ST-PAUL-LEZ-DURANCE, FRANCE

The world's largest fusion experiment is finally beginning to take shape. Workers at a vast site in southern France have dug the 17-metre-deep pit that will house the ITER reactor, and will soon install 500 pillars of steel-reinforced concrete that should protect the machine during an earthquake. But even as they toil, a quake halfway around the world has struck a blow to the project.

The 11 March earthquake and tsunami that hit Japan, one of seven partners in ITER, severely damaged key facilities for testing the reactor's components. Unless repairs can be made or work reassigned quickly, the damage could cause a delay of "perhaps several years", according to Osamu Motojima, ITER's director. Motojima says that he and his team are looking at ways to reduce the impact. "At present my target is less than one year's delay," he says.

ITER's first experiments have already been pushed back from 2016 to 2019 , and the project has suffered serious cost overruns since its partners agreed to go ahead in 2006. Any extra delays are likely to increase political pressure to find cost savings and speed up work.

The giant reactor is designed to prove that useful energy can be extracted from the fusion of hydrogen isotopes. By trapping the hydrogen using powerful superconducting magnets and heating it to the point of fusion at 150 million ${ }^{\circ} \mathrm{C}$ with specially designed 
- heating systems, ITER is supposed to produce ten times more energy than it consumes. The Naka Fusion Institute of the Japan Atomic Energy Agency, which is about 100 kilometres north-east of Tokyo, was a key facility for testing and developing the magnets and heating systems. But it was hit hard by the quake. "The buildings are damaged and we can't go inside," says Hiroshi Kataoka, director of the fusion division at Japan's Ministry of Education, Culture, Sports, Science and Technology, which oversees Japan's contributions to the ITER project. "We are not sure, but it may have some impact on our ability to deliver products on time."

The magnet test facilities are particularly important for the project. Late last year, a sample of superconducting cable to be used in a central magnet failed testing at a facility in Switzerland (see Nature 471, 150; 2011). Follow-up tests at the Naka institute were expected to help determine the cause of the failure and aid any redesign of the cable, which is being manufactured in Japan. The cable factories themselves seem to be undamaged, according to Richard Hawryluk, one of ITER's deputy directors-general.

Motojima says he is reluctant to shift work away from Japan unless absolutely necessary, but if the facilities cannot be repaired within six months, he says that he will seek arrangements with other partners in the project. A new schedule and any adjustments to the reactor's work plan must be ready by December, he says.

Meanwhile, the project's financial woes continue. Since 2006, ITER's construction costs have roughly tripled to around $€ 15$ billion (US $\$ 21$ billion). The European Union, which is paying for some $45 \%$ of the project, has yet to find the additional $€ 1.3$ billion it needs to meet its near-term commitment in 2012 and 2013. Anne Jensen, a member of the European parliament from Denmark who sits on the parliament's budget committee, says that she and other members are generally supportive of the project, as long as it does not draw money away from other areas of research. "We think ITER is an interesting project, but it should not be at the expense of the development of wind energy or smart grids," she says. But she adds that she is optimistic that ITER's funding can be found by the 2012 deadline.

The other partners - Russia, South Korea, India, China and the United States, which along with Japan are each contributing around 9\% to the construction - are also struggling to come up with additional funding. In the United States, for example, battles in Congress over discretionary spending have meant that ITER got its 2011 allocation of $\$ 80$ million only last month.

Given the variety of financial and technical difficulties facing ITER, a further delay of "a couple of years" is probably inevitable, says Stephen Dean, president of advocacy organization Fusion Power Associates in Gaithersburg, Maryland. But, he adds, "that doesn't mean that they can't get it done". .

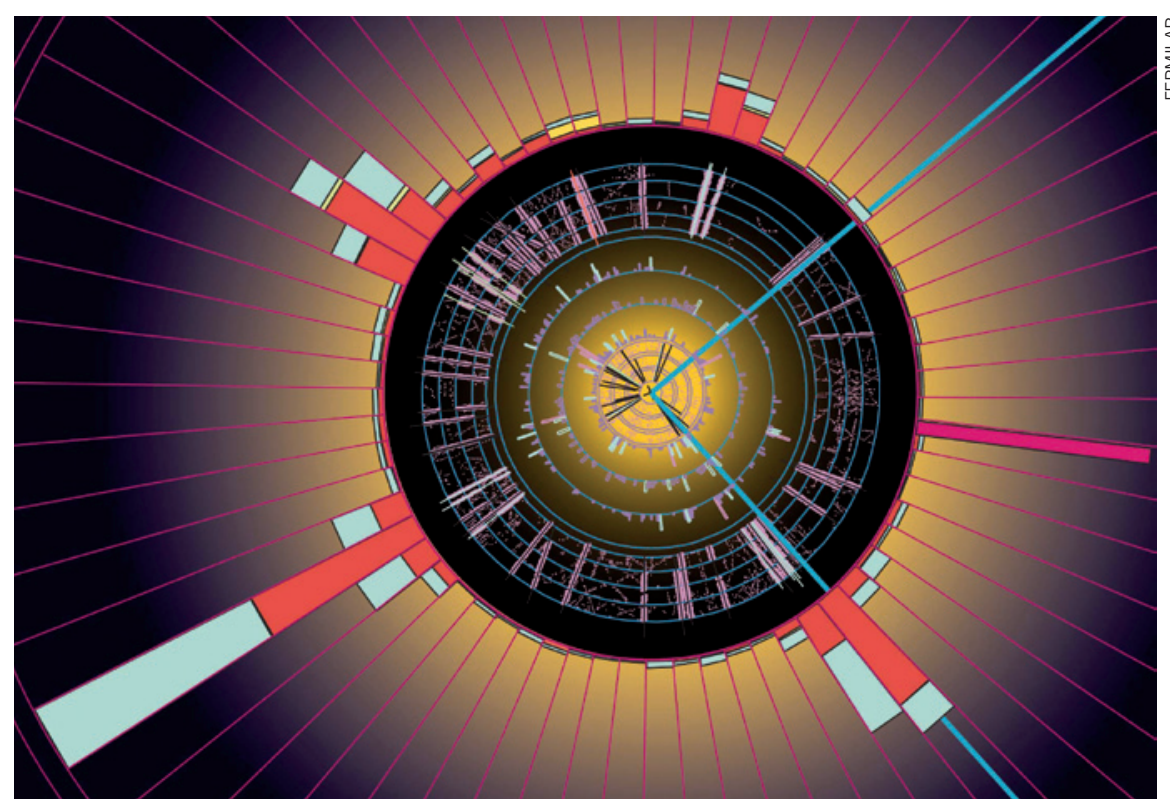

Data from Fermilab, such as this reconstruction of two top quarks, could be lost to physicists forever.

PARTICLE PHYSICS

\section{Tevatron's legacy set to disappear}

\section{Lack of long-term preservation plan threatens to leave key information inaccessible for future analysis.}

\section{BY EUGENIE SAMUEL REICH}

$\mathrm{F}$ our months before the Tevatron shuts down for good, physicists at Fermilab's giant particle collider near Batavia, Illinois, are pulling out all the stops to collect every last bit of data that they can. But some worry about what will eventually happen to the trove of data - approaching 20 petabytes $\left(20 \times 10^{15}\right.$ bytes $)$ - amassed over the machine's 26-year life. Although there is funding to continue sifting the data for traces of the Higgs boson and other subatomic prizes for the next five years, so far there is no plan and no budget for preserving them in the longer term.

At a workshop on data preservation at Fermilab on 16-18 May, some physicists called for that to change, arguing that Tevatron data could prove useful as an independent check on its successor, the Large Hadron Collider (LHC) now operating at CERN, Europe's particle-physics lab near Geneva, Switzerland. If researchers suspect that the LHC has spotted new physics, particularly at the lower end of its energy range, the claim could be tested for consistency with Tevatron

data, says Rob Roser, spokesman for the Collider Detector at Fermilab (CDF), one of the Tevatron's two principal experiments.

Although many fields of science, from genomics to astrophysics, put substantial resources into archiving data and making them publicly available, the norm in particle physics has, until recently, been very different. When the analysis of data from an experiment trickles to a halt, researchers typically move on. The data languish or are even destroyed to make storage space available for something else. When the Tevatron was built, "we did not think about data preservation”, says Qizhong Li, computing coordinator for D0, the other main experiment at the Tevatron. "This is a rather new concept."

Both D0 and the CDF expect to lose their dedicated computing infrastructure over the next five years. A gradual loss of knowledge about how to deal with the complex

$\rightarrow$ NATURE.COM For more on how to cope with big data sets, see: go.nature.com/vnklyt data, which includes raw detector readouts, reconstructed particle trajectories and higherlevel analyses, could also present a serious 